\title{
Unpredictability and uncertainty in anxiety: a new direction for emotional timing research
}

\author{
Jessica I. Lake ${ }^{1,2 *}$ and Kevin S. LaBar ${ }^{1,2}$ \\ Center for Cognitive Neuroscience, Duke University, Durham, NC, USA \\ 2 Department of Psychology and Neuroscience, Duke University, Durham, NC, USA \\ *Correspondence: jessica.lake@duke.edu
}

Interest in the relationship between emotion and time perception has noticeably increased in the past few years (Buhusi and Meck, 2005; Droit-Volet and Meck, 2007; Craig, 2009; Droit-Volet et al., 2011). Most of this recent work has used emotional stimuli, such as faces (e.g., Droit-Volet et al., 2004; Tipples, 2008), pictures (e.g., Angrilli et al., 1997; Grommet et al., 2011), and sounds (e.g., Noulhaine et al., 2007) to understand how emotion can change the subjective experience of short intervals of time. Efforts have largely focused on determining what these findings reveal about how time can be distorted and identifying the mechanisms responsible for flexibly modulating these distortions. In this issue, Schirmer (2011) reviews various theories that attempt to explain the mechanisms underlying emotional influences on time perception and proposes a hybrid theory to better support findings in the field. Further research will be necessary to support or contradict the proposed mechanistic influences of emotion on timing. While the value of this work is clear, it is equally important to address how timing research can inform affective science and affective disorders, a question that has thus far received little attention within the field. Specifically, a better understanding of how time is perceived in anxiety-provoking contexts could be important in fully appreciating the processes underlying the experience of anxiety.

Many of the first studies of time perception and anxiety analyzed estimates of elapsed time under stressful conditions (e.g., Langer et al., 1961; Hare, 1963; Watts and Sharrock, 1984; Loftus et al., 1987). While these studies consistently reported overestimation of time and were ecologically relevant, they were limited in that they relied on small numbers of trials and retrospective reports, which have been argued to reflect memory, rather than timing, processes per se (Zakay, 1990). Using standardized emotional stimuli such as pictures and film clips, more recent studies have added support to the idea that increased fear and anxiety are correlated with the overestimation of time intervals (e.g., Droit-Volet et al., 2011; Grommet et al., 2011). At the same time, recent work on anxiety and related disorders has focused on the role of ambiguity (e.g., Nader and Balleine, 2007; Shankman et al., 2011; Zweifel et al., 2011). Using work on timing and time perception to address the influence of ambiguity on anxiety could provide a unique perspective from which to further advance our understanding of these clinical disorders.

Anxiety is defined as a state of prolonged fear or arousal in response to a threat that is ambiguous or unspecific (Lang et al., 2000). Ambiguity refers to a situation or context in which a threat may take various forms, and different predictions and behaviors based on these predictions may subsequently occur (Whalen, 1998). Temporal unpredictability (ambiguity in when an event will occur) and probabilistic uncertainty (ambiguity in how likely an event is to occur) are two types of threat ambiguity. Human and non-human animal studies suggest that both unpredictability and uncertainty modulate anxietylike behaviors and activity in brain regions associated with anxiety (Hsu et al., 2005; Rosen and Donley, 2006; Herry et al., 2007).

Most studies showing an increase in anxiety associated with temporal unpredictability have used paradigms involving anticipation of negative emotional events (e.g., Grillon et al., 2006). Note that this approach contrasts with typical time perception studies in which emotion is manipulated phasically through alterations in the sensory features of a stimulus whose duration is to be timed. In Grillon et al. (2004), anxiety was operationally defined as the magnitude of a startle response (Brown et al., 1951) during cue-free periods within an aversive conditioning paradigm (contextpotentiated startle). Context-potentiated startle was greater when surrounding cues were not predictive of when aversive events occurred (i.e., aversive events were perceived as occurring randomly) compared to cuefree periods within the context of cues that reliably predicted the temporal occurrence of aversive events. Simply cuing previously unpredictable shocks also reduces contextpotentiated startle responses (Fonteyne et al., 2010). Together, these findings suggest that temporal unpredictability increases anxiety levels. The aversive nature of unpredictability is further supported by studies showing that animals prefer to receive predictable over unpredictable shocks (Gliner, 1972; Badia et al., 1979). Unpredictability on its own (i.e., without an explicit association with an aversive stimulus) may also be anxiogenic. In a translational study examining both a mouse model and healthy human participants, Herry et al. (2007) found that manipulating the unpredictability of neutral tones increased anxiety-like behaviors. Furthermore, this study implicated the amygdala, a structure commonly associated with fear and anxiety (e.g., LaBar et al., 1998; Davis et al., 2010; Tye et al., 2011), in the monitoring of unpredictability. Across species evidence of sustained activity in the amygdala was interpreted as reflecting modified habituation processes to allow individuals to remain prepared for action in the face of unpredictability.

In addition to temporal unpredictability, probabilistic uncertainty also seems to modulate anxiety. While different relationships between the probability of aversive events and anxiety have been proposed when those probabilities are known to the subject (e.g., Epstein and Roupenian, 1970; Bankart and Elliott, 1974; Loewenstein et al., 2001), increased anxiety levels are evident when subjects are unaware of event contingencies. Sarinopoulos et al. (2010) found that, in retrospective estimates, healthy participants overestimated how often a cue that ambiguously predicted negative stimuli $(50 \%$ chance of negative 
stimulus presentation following cue) was followed by an aversive event. In this study, increased activity in the amygdala and insula was found during ambiguous cues relative to cues that perfectly predicted negative stimuli. The magnitude of this difference was further correlated with the degree of overestimation in retrospective reports. Ambiguous cues are also associated with increased skin conductance responses (Grupe and Nitschke, 2011). These results suggest that, like unpredictability, individuals find uncertain probabilities aversive. Neuroeconomic studies have also provided evidence supporting the role of the amygdala (e.g., Hsu et al., 2005) and insula (e.g., Preuschoff et al., 2008) in the processing of decisions under uncertainty.

While time perception research has shown that subjective time is sensitive to fear and anxiety (e.g., Campbell and Bryant, 2007; Bar-Haim et al., 2010), there is a paucity of research directly addressing the function of ambiguity in time distortions. Based on the work cited above showing that anxiety is influenced by different types of ambiguity, we predict that the experience of time may also be sensitive to manipulations of threat ambiguity and, specifically of interest here, to manipulations of unpredictability and uncertainty. Fearful and angry faces, which are both considered social indicators of threat, tend to be overestimated in time (Droit-Volet et al., 2004; Bar-Haim et al., 2010; Tipples, 2011, but see Tipples, 2008). Temporal overestimation of fearful faces is further modulated by individual differences in trait anxiety (Bar-Haim et al., 2010, but see Tipples, 2011). The overestimation of fearful faces is particularly relevant in considering the influence of ambiguity on time perception. Whalen (1998) proposed that fearful facial expressions are ambiguous stimuli in experimental designs because the source of threat resulting in the expressed fear is unknown to participants. Findings indicating that fearful faces increase time estimates therefore provide preliminary support for the idea that threat ambiguity can influence time perception.

In Droit-Volet et al. (2010), participants judged a probe duration that began after a neutral cue or a cue that predicted an aversive event. Probe durations were overestimated following the threat cue compared to the neutral cue and a longer anticipation period prior to the delivery of the aversive event resulted in an even greater overestimation of time. These findings suggest that the magnitude of time distortion was correlated with the degree of anticipatory anxiety experienced by the participants. In this study, the cues predicting an aversive event were always temporally predictable and $100 \%$ reinforced. Manipulating unpredictability and uncertainty in a similar paradigm by varying the anticipation period within participants or altering reinforcement probabilities could reveal more about the relationship between anxiety and time. If unpredictability and uncertainty increase aversiveness (Herry et al., 2007; Sarinopoulos et al., 2010), it may be predicted that these anxiety-provoking contexts would also increase distortions of subjective time.

While the evidence provided above implicates both temporal unpredictability and probabilistic uncertainty in increased anxiety, these two types of ambiguity may be functionally dissociable across clinical populations. Grillon et al. (2008) found that panic disorder patients showed greater context-potentiated startle in a temporally unpredictable aversive condition compared to a predictable condition with temporally cued (but probabilistically uncertain) aversive sounds. Similar results were found for post-traumatic stress disorder patients using a comparable study paradigm (Grillon et al., 2009). The authors predicted these results based on the idea that both disorders are characterized by anxiety resulting from the unpredictability of aversive events. Interestingly, Grillon et al. (2009) found that generalized anxiety disorder (GAD) patients did not show the same pattern of anxietylike responses, suggesting that the anxiety experienced by GAD patients might be qualitatively different. It is important to consider that while the predictable condition in this study was temporally invariant, a probabilistic reinforcement rate was used such that the cue did not perfectly predict the aversive stimulus. It is therefore possible that GAD patients had an enhanced aversive response to the probabilistic uncertainty associated with this cue. Indeed, GAD patients showed the highest context-potentiated startle in the predictable condition, though this finding was not statistically significant. The hypothesis that GAD patients find probabilistic uncertainty aversive is indirectly supported by Krain et al. (2008), who found that adolescent GAD patients with high intolerance of uncertainty (IU) scores showed greater activity in the amygdala than controls when contrasting "pure" uncertainty (50\% probability of a correct response) with other task conditions. These patients also rated the $50 \%$ probability condition as more anxietyprovoking than control participants. IU is believed to correlate with worry (Dugas et al., 1997), a characteristic feature of GAD, according to the Diagnostic and Statistical Manual of Mental Disorders - 4th edn (American Psychiatric Association, 1994). Interestingly, while IU may be positively correlated with probabilistic uncertainty, it was found to be negatively correlated with context-potentiated startle responses in a temporally unpredictable context (Nelson and Shankman, 2011). College students with higher IU scores showed decreased contextpotentiated startle responses. Because high IU scores are associated with GAD, this supports Grillon et al. (2009) and the idea that GAD is not associated with increased context-potentiated startle during temporal unpredictability. Probabilistic uncertainty and temporal unpredictability may, therefore, differentially modulate anxiety and distinguish different anxiety-related disorders. Further work with these clinical populations is necessary and could have important implications for nosology and treatment.

While studies have demonstrated time distortions in non-anxious patient populations (Meck, 1996, 2005; Berlin and Rolls, 2004; Melgire et al., 2005; Penney et al., 2005; Allman and Meck, 2011), examinations of how time may be distorted in individuals with anxiety disorders are lacking. It is likely that time is distorted to a greater extent during periods of increased threat and anxiety in clinical populations suffering from anxiety disorders than in healthy controls. It is also predicted, based on current research on unpredictability and uncertainty, that these two forms of threat ambiguity may differentially influence time distortions across clinical groups and could help further characterize the differences between certain anxiety-related populations. For example, panic and post-traumatic stress disorder patients might show greater time distortions resulting from unpredictable stimuli, whereas GAD patients might show greater distortions resulting from probabilistic uncertainty. Such findings would indicate 
that time perception is intimately related to the way in which anxiety is experienced and how individuals respond to aversive events.

Taking this idea a step further, the hypothesis that time distortions are yoked to the experience of anxiety could potentially open the door to new therapies focused on using cognitive strategies to reduce these distortions and, as a result, reduce feelings of anxiety. A study by Mella et al. (2011) provides preliminary evidence that paying attention to time rather than emotion can reduce physiological arousal as a form of emotion regulation. Future work could address the potential for attending to time in reducing the aversiveness of ambiguous stimuli. This therapeutic direction would represent a novel treatment in the control of anxiety disorders.

Finally, research on ambiguity and time perception could increase our understanding of anxiety even further if future studies combined neuroimaging techniques with psychological studies of behavior. Only a few studies have examined the neural correlates of anxiety and time perception (Meck and MacDonald, 2007; Gan et al., 2009). The findings of Meck and MacDonald (2007), in particular, indicate that the amygdala may be critical for distortions in timing arising from the threat of an aversive event. Other researchers have suggested the importance of the insula in the relationship between emotion and time (Craig, 2009; Schirmer, 2011). Research showing that these brain regions mediate the effects of unpredictability and uncertainty on time distortions would help in better understanding the biological mechanisms underlying the experience of anxiety.

It is suggested here that researchers in the field of timing and time perception consider how the study of emotional timing may benefit not just the field of time perception, but that of emotion and affective disorders as well. Addressing the influence of ambiguity on anxiety and how different aspects of ambiguity interact with time perception could help improve our understanding of the mechanisms underlying the experience of anxiety, how these processes become impaired in clinical populations, and potential treatment avenues (Meck et al., 2008; Allman and Meck, 2011; Coull et al., 2011; Gu et al., 2011). While the present paper only addresses the potential influence of unpredictability and uncertainty on time distortions in the context of the anticipation of aversive events, it is equally likely that these components of ambiguity may also influence time during the anticipation of positive events, an additional avenue for future research. Overall, there is great promise in bridging psychological and neurobiological disciplines by addressing current topics in the field of emotion to increase the value and applicability of time perception research.

\section{ACKNOWLEDGMENT}

This work was supported by a National Science Foundation Graduate Fellowship to Jessica I. Lake.

\section{REFERENCES}

Allman, M. J., and Meck, W. H. (2011). Pathophysiological distortions in time perception and timed performance. Brain doi: 10.1093/brain/ awr210. (in press).

American Psychiatric Association (APA). (1994). DSM-IV: Diagnostic and Statistical Manual of Mental Disorders, 4th Edn. Washington, DC: American Psychiatric Press.

Angrilli, A., Cherubini, P., Pavese, A., and Manfredini, S. (1997). The influence of affective factors on time perception. Percept. Psychophys. 59, 972-982.

Badia, P., Harsh, J., and Abbott, B. (1979). Choosing between predictable and unpredictable shock conditions: data and theory. Psychol. Bull. 86, 1107-1131.

Bankart, C. P., and Elliott, R. (1974). Heart rate and skin conductance in anticipation of shocks with varying probability of occurrence. Psychophysiology 11, 160-174.

Bar-Haim, Y., Kerem, A., Lamy, D., and Zakay, D. (2010). When time slows down: the influence of threat on time perception in anxiety. Cogn. Emot. 24, 255-263.

Berlin, H. A., and Rolls, E. T. (2004). Time perception, impulsivity, emotionality, and personality in selfharming borderline personality disorder patients. J. Pers. Disord. 18, 358-378.

Brown, J. S., Kalish, H. I., and Farber, I. E. (1951). Conditioned fear as revealed by magnitude of startle response to an auditory stimulus. J. Exp. Psychol. 41, 317-328.

Buhusi, C. V., and Meck, W. H. (2005). What makes us tick? Functional and neural mechanisms of interval timing. Nat. Rev. Neurosci. 6, 755-765.

Campbell, L. A., and Bryant, R. A. (2007). How time flies: a study of novice skydivers. Behav. Res. Ther. 45, 1389-1392.

Coull, J. T., Cheng, R. K., and Meck, W. H. (2011). Neuroanatomical and neurochemical substrates of timing. Neuropsychopharmacology 36, 3-25.

Craig, A. D. (2009). Emotional moments across time: a possible neural basis for time perception in the anterior insula. Philos. Trans. R. Soc. Lond. B Biol. Sci.364, 1933-1942.

Davis, M., Walker, D. L., Miles, L., and Grillon, C. (2010). Phasic vs sustained fear in rats and humans: role of the extended amygdala in fear vs anxiety. Neuropsychopharmacology 35, 105-135.
Droit-Volet, S., Brunot, S., and Niedenthal, P. (2004) Perception of the duration of emotional events. Cogn. Emot. 18, 849-858.

Droit-Volet, S., Fayolle, S. L., and Gil, S. (2011). Emotion and time perception: effects of film-induced mood. Front. Integr. Neurosci. 5:33. doi: 10.3389/ fnint.2011.00033

Droit-Volet, S., and Meck, W. H. (2007). How emotions colour our perception of time. Trends Cogn. Sci. (Regul. Ed.) 11, 504-513.

Droit-Volet, S., Mermillod, M., Cocenas-Silva, R., and Gil, S. (2010). Expectancy of a threatening event on time perception in human adults. Emotion 10, 908-914.

Dugas, M. J., Freeston, M. H., and Ladouceur, R. (1997). Intolerance of uncertainty and problem orientation in worry. Cogn. Ther. Res. 21, 593-606.

Epstein, S., and Roupenian, A. (1970). Heart rate and skin conductance during experimentally induced anxiety: the effect of uncertainty about receiving a noxious stimulus. J. Pers. Soc. Psychol. 16, 20-28.

Fonteyne, R., Vervliet, B., Hermans, D., Baeyens, F., and Vansteenwegen, D. (2010). Exposure to the context and removing the unpredictability of the US: two methods to reduce contextual anxiety compared. Biol. Psychol. 85, 361-369.

Gan, T., Wang, N., Zhang, Z., Li, H., and Luo, Y. (2009). Emotional influences on time perception: evidence from event-related potentials. Neuroreport 20, 839-843.

Gliner, J. A. (1972). Predictable vs. unpredictable shock: preference behavior and stomach ulceration. Physiol. Behav. 9, 693-698.

Grillon, C., Baas, J. M. P., Cornwell, B., and Johnson, L. (2006). Context conditioning and behavioral avoidance in a virtual reality environment: effect of predictability. Biol. Psychiatry 60, 752-759.

Grillon, C., Baas, J. P., Lissek, S., Smith, K., and Milstein, J. (2004). Anxious responses to predictable and unpredictable aversive events. Behav. Neurosci. 118, 916-924.

Grillon, C., Lissek, S., Rabin, S., McDowell, D., Dvir, S., and Pine, D.S. (2008). Increased anxiety during anticipation of unpredictable but not predictable aversive stimuli as a psychophysiologic marker of panic disorder. Am. J. Psychiatry 165, 898-904.

Grillon, C., Pine, D. S., Lissek, S., Rabin, S., Bonne, O., and Vythilingham, M. (2009). Increased anxiety during anticipation of unpredictable aversive stimuli in posttraumatic stress disorder but not in generalized anxiety disorder. Biol. Psychiatry 66, 47-53.

Grommet, E. K., Droit-Volet, S., Gil, S., Hemmes, N. S., Baker, A. H., and Brown, B. L. (2011). Time estimation of fear cues in human observers. Behav. Processes $86,88-93$.

Grupe, D. W., and Nitschke, J. B. (2011). Uncertainty is associated with biased expectancies and heightened responses to aversion. Emotion 11, 413-424.

Gu, B. M., Cheng, R. K., Yin, B., and Meck, W. H. (2011). Quinpirole-induced sensitization to noisy/sparse periodic input: temporal syhchronization as a component of obsessive-compulsive disorder. Neuroscience $179,143-150$.

Hare, R. D. (1963). The estimation of short temporal intervals terminated by shock. J. Clin. Psychol. 19, 378-380.

Herry, C., Bach, D. R., Esposito, F., Di Salle, F., Perrig, W. J., Scheffler, K., Luthi, A., and Seifritz, E. (2007). Processing of temporal unpredictability in human and animal amygdala. J. Neurosci. 27, 5958-5966. 
Hsu, M., Bhatt, M., Adolphs, R., Tranel, D., and Camerer, C. F. (2005). Neural systems responding to degrees of uncertainty in human decision-making. Science 310, 1680-1683.

Krain,A.L., Gotimer, K., Hefton, S., Ernst, M., Castellanos, X., Pine, D. S., and Milham, M. P. (2008).A functional magnetic resonance imaging investigation of uncertainty in adolescents with anxiety disorders. Biol. Psychiatry 63, 563-568.

LaBar, K. S., Gatenby, J. C., Gore, J. C., LeDoux, J. E., and Phelps, E. A. (1998). Human amygdala activation during conditioned fear acquisition and extinction: a mixed-trial fMRI study. Neuron 20, 937-945.

Lang, P. J., Davis, M., and Öhman, A. (2000). Fear and anxiety: animal models and human cognitive psychophysiology. J. Affect. Disord. 61, 137-159.

Langer, J., Wapner, S., and Werner, H. (1961). The effect of danger upon the experience of time. Am. J. Psychol. 74, 94-97.

Loewenstein, G. F., Weber, E. U., Hsee, C. K., and Welch, N. (2001). Risk as feelings. Psychol. Bull. 127, 267-286.

Loftus, E. F., Schooler, J. W., Boone, S. M., and Kline, D. (1987). Time went by so slowly: overestimation of event duration by males and females. Appl. Cogn. Psychol. 1, 3-13.

Meck, W. H. (1996). Neuropharmacology of timing and time perception. Brain Res. Cogn. Brain Res. 3, 227-242.

Meck, W.H. (2005). Neuropsychology of timing and time perception. Brain Cogn. 58, 1-8.

Meck, W. H., and MacDonald, C. J. (2007). Amygdala inactivation reverses fear's ability to impair divided attention and make time stand still. Behav. Neurosci. 121, 707-720.

Meck, W. H., Penney, T. B., and Pouthas, V. (2008). Cortico-striatal representation of time in animals and humans. Curr. Opin. Neurobiol. 18, 145-152.

Melgire, M., Ragot, R., Samson, S., Penney, T. B., Meck, W. H., and Pouthas, V. (2005). Auditory/ visual duration bisection in patients with left or right medial-temporal lobe resection. Brain Cogn. 58, 119-124.

Mella, N., Conty, L., and Pouthas, V. (2011). The role of physiological arousal in time perception: psychophysiological evidence from an emotion regulation paradigm. Brain Cogn. 75, 182-187.

Nader, K., and Balleine, B. (2007). Ambiguity and anxiety: when a glass half full is empty. Nat. Neurosci. 10, 807-808.

Nelson, B. D., and Shankman, S. A. (2011). Does intolerance of uncertainty predict anticipatory startle responses to uncertain threat? Int. J. Psychophysiol. 81, 107-115.

Noulhaine, M., Mella, N., Samson, S., Ragot, R., and Pouthas, V. (2007). How emotional auditory stimuli modulate time perception. Emotion 7, 697-704.

Penney, T. B., Meck, W. H., Roberts, S. A., Gibbon, J., and Erlenmeyer-Kimling, L. (2005). Interval-timing deficits in individuals at high risk for schizophrenia. Brain Cogn. 58, 109-118.

Preuschoff, K., Quartz, S. R., and Bossaerts, P. (2008). Human insula activation reflects risk prediction errors as well as risk. J. Neurosci. 28, 2745-2752.

Rosen, J. B., and Donley, M. P. (2006). Animal studies of amygdala function in fear and uncertainty: relevance to human research. Biol. Psychol. 73, 49-60.

Sarinopoulos, I., Grupe, D. W., Mackiewicz, K. L., Herrington, D., Lor, M., Steege, E. E., and Nitschke, J. B. (2010). Uncertainty during anticipation modulates neural responses to aversion in human insula and amygdala. Cereb. Cortex 20, 929-940.

Schirmer, A. (2011). How emotions change time. Front. Integr. Neurosci. (in press).

Shankman, S. A., Robison-Andrew, E. J., Nelson, B. D., Altman, S. E., and Campbell, M. L. (2011). Effects of predictability of shock timing and intensity on aversive responses. Int. J. Psychophysiol. 80, 112-118.
Tipples, J. (2008). Negative emotionality influences the effects of emotion on time perception. Emotion 8, 127-131.

Tipples, J. (2011). When time stands still: fear-specific modulation of temporal bias due to threat. Emotion $11,74-80$

Tye, K. M., Prakash, R., Kim, S., Fenno, L. E., Grosenick, L., Zarabi, H., Thompson, K. R., Gradinaru, V., Ramakrishnan, C., and Deisseroth, K. (2011). Amygdala circuitry mediating reversible and bidirectional control of anxiety. Nature 471, 358-362.

Watts, F. N., and Sharrock, R. (1984). Fear and time estimation. Percept. Mot. Skills 59, 597-598.

Whalen, P. (1998). Fear, vigilance, and ambiguity: initial neuroimaging studies of the human amygdala. Curr. Dir. Psychol. Sci. 7, 177-188.

Zakay, D. (1990). "The evasive art of subjective time measurement: some methodological dilemmas," in Cognitive Models of Psychological Time, ed. R. A. Block (Hillsdale, NJ: Lawrence Erlbaum), 59-84.

Zweifel, L. S., Fadok, J. P., Argilli, E., Garelick, M. G., Jones, G. L., Dickerson, T. M. K., Allen, J. M., Mizumori, S. J. Y., Bonci, A., and Palmiter, R. D. (2011). Activation of dopamine neurons is critical for aversive conditioning and prevention of generalized anxiety. Nat. Neurosci. $14,620-628$.

Received: 15 August 2011; accepted: 29 August 2011; published online: 19 September 2011.

Citation: Lake JI and LaBar KS (2011) Unpredictability and uncertainty in anxiety: a new direction for emotional timing research. Front. Integr. Neurosci. 5:55. doi: 10.3389/ fnint.2011.00055

Copyright ( $(2011$ Lake and LaBar. This is an open-access article subject to a non-exclusive license between the authors and Frontiers Media SA, which permits use, distribution and reproduction in other forums, provided the original authors and source are credited and other Frontiers conditions are complied with. 